\title{
Telaah Metode-metode Pendeteksi Kebohongan
}

\author{
I Gede Aris Gunadi ${ }^{* 1}$, Agus Harjoko ${ }^{2}$ \\ ${ }^{1}$ Jurusan Pendidikan Fisika, FMIPA, Undiksha Singaraja \\ ${ }^{2}$ Lab Elektronika Instrumentasi, FMIPA, UGM, Yogyakarta \\ e-mail : " 1 aria_sukaat@yahoo.com, ${ }^{2}$ aharjoko@ugm.ac.id
}

\begin{abstract}
Abstrak
Pendeteksi kebohongan adalah aplikasi yang menerapkan berbagai cabang ilmu pengetahuan(psikologi,kedokteran,biologi,fisika,komputer,dan lain lain). Aplikasi pendeteksi kebohongan sangatlah berguna terutama dikalangan penegak hukum, untuk mengungkap fakta fakta. Pada prinsipnya metode pendekteksi kebohongan bekerja berdasarkan perubahan respon fisiologis tubuh manusia, yang diakibatkan oleh usahanya untuk menutupi kebohongannya.Dalam paper ini akan dibahas berbagai pendekatan metode yang telah dikembangkan untuk mendeteksi kebohongan,diantaranya deteksi kebohongan berdasarkan konduktivitas kulit, bentuk tulisan tangan, isi ( content tulisan), analisis suara, termograpy, dan gesture.
\end{abstract}

Kata kunci-Lie detector, Detection Deception, Polygraph, PDD Test.

\section{Abstract}

Lie detector is an application that applying various of knowledge such as psychology,medicine,biology,physics, computer, and etc. This application is very useful especially among law officer to detect deception. In principle, the lie detector's methods work based on change of fisilogy respon at human being body. The change of psiology respon is caused by effort to keep their deception. In this papers, we present an approach various methods of lie detection which have been developed. we will present lie detection based on skin conductivity respon, handwriting form, article content, voice analysis, image infrared, and gesture.

Keywords - Lie detecotor, Detection Deception, Polygraph, PDD( polygraph Detection deception) Test.

\section{PENDAHULUAN}

$\mathrm{M}$ etode pendeteksi kebohongan sangatlah penting bagi orang orang yang bergerak dibidang penegak hukum ( kepolisian, Kejaksaan,dan pengadilan), mungkin juga bisa dimanfaatkan para staf HRD di perusahaan ketika menguji staf karyawan baru. Berdasarkan sejarah perkembangan metode pendeteksian kebohongan telah mengalami perkembangan yang luar biasa. Pada zaman dahulu untuk membuat orang mengakui kebohongan dan mengungkap kebenaran, kadang kadang disertai penyiksaan . Secara hukum hal seperti ini tentu tidak bisa dibenarkan, dan akurasi hasilnya tidak bisa dipertanggung jawabkan. Pada tahun 1920 telah mulai dikembangkan tes polygraph ( tes untuk mendeteksi kebohongan ).

Psikologi sebagai salah cabang ilmu pengetahuan, telah mempelajari secara khusus permasalahan ini dalam suatu kajian Psychophisiologi. Sebuah lie detector berkerja dengan mengamati perubahan respon fisilogis tubuh ( seperti detak jantung, detak ( cepat lambat ) pernapasan, perubahan produksi keringat, panas tubuh, getar suara, dan lain lain). Tingkat keakuratan lie detector berkisar antara 60\%- 90\% [1]. Psycophisiology secara khusus 
membahas hubungan kondisi kejiwaan seseorang dengan kondisi fiologis tubuh. Pada prinsipnya orang yang berbohong akan merasa tertekan, stress,terancam. Perasaan tersebut kemudian ditunjukan dalam bentuk respon fisiologis [2] Pada jaman dahulu orang cina juga sudah menerapkan pengetahuan ini untuk mendeteksi kebohongan, untuk membuktikan orang berbohong diuji dengan menyuruh orang yang dicurigai mengunyah tepung beras dan memuntahkan kembali. Apabila tepung beras yang dimuntahkan kering maka orang tersebut dianggap bersalah, penurunan produksi air liur di interprestasikan sebagai bentuk ketakutan karena berbohong. Naik turun produksi air liur adalah gejala fisiologis pada tubuh manusia [3]. Pada dasarnya dalam tubuh manusia terdapat beberapa signal biologis yang dapat digunakan untuk mendeteksi adanya kebohongan, diantaranya signal respon sifat hantaran listrik pada kulit, signal tekanan darah, signal detak jantung, signal otot (microtremor) penghasil suara, signal temperatur tubuh [4] .

Berdasarkan hal ini dikembangkan berbagai instrument atau alat untuk mendeteksi kebohongan. Pada peper ini akan dibahas beberapa metode untuk mendeteksi kebohongan diantaranya, pendeteksi kebohongan berdasarkan daya hantar listrik pada kulit, pendeteksi kebohongan berdasarkan isi (content) tulisan, pendeteksi kebohongan berdasarkan bentuk bentuk tulisan tangan ( Grafologi), pendeteksi kebohongan berdasarkan analisa suara, pendeteksi kebohongan berdasarkan termograpy (image infrared), dan pendeteksi kebohongan berdasarkan gesture.

\section{METODE PENELITIAN}

Penelitian ini sifatnya adalah review berbagai sumber penelitian yang membahas tentang metode pendeteksi kebohongan. Dalam review sumber kepustakaan ini dilakukan klasifikasi metode pendeteksi kebohongan berdasarkan prinsip kerjanya. Seperti telah diuraikan prinsip kerja dari alat pendeteksi kebohongan adalah, mengamati respon tubuh yang mengalami kondisi stress. Respon tubuh tersebut diamati dalam banyak bentuk, sebagai contoh orang yang berbohong akan mengalami perubahan respon pada produksi kelenjar keringat, orang yang berbohong cenderung berkeringat dibanding orang yang jujur, karena keringat merupakan larutan elektrolit ( larutan yang mampu menghantarkan listrik), sehingga kebohongan ditentukan dengan melihat perubahan daya hantar listrik pada kulit[5]. Secara umum proses pendeteksian kebohongan dapat ditunjukan pada Gambar 1.

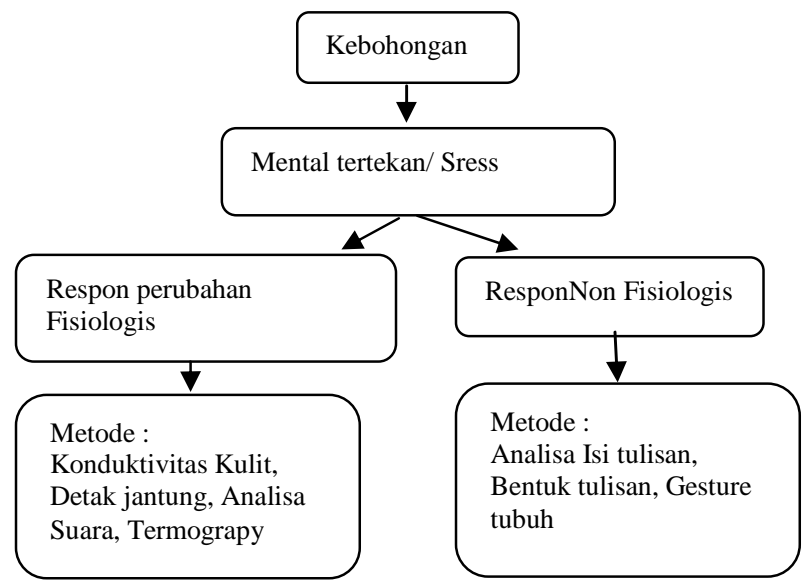

Gambar 1 Klasifikasi metode pendeteksi kebohongan berdasarkan bentuk respon tubuh

Seperti telah diuraikan di atas secara alamiah orang yang berbohong akan mengalami tekanan secara mental atau stress. Prilaku mental yang tertekan akibat berbohong dapat dilakukan secara langsung dengan melihat perubahan fisiologis tubuh secara langsung maupun secara tidak langsung ( bukan respon fisiologis) misalnya dari bentuk tulisan tangan. Sedangkan berdasarkan operasional pengunaan alat pendeteksi kebohongan, metode pendeteksi

IJCCS Vol. 6, No. 2, July 2012: 35 - 46 
kebohongan dapat diklasifikasikan menjadi dua, operasional yang invansive dan Non invansive. Metode invansive artinya untuk melakukan pengujian harus ada kontak antara alat dengan tubuh subjek yang sedang diinvestigasi (biasanya antara tubuh dengan detector dihubungkan dengan kabel konektor). Metode yang non invansive memiliki kelebihan karena secara psikologi tidak menganggu subjek yang sedang diinvestigasi.

\section{HASIL DAN PEMBAHASAN}

Pada bagian ini akan dibahas tentang beberapa metode pendeteksi kebohongan, diantaranya, pendeteksi kebohongan berdasarkan konduktivitas kulit, isi tulisan, bentuk tulisan tangan, analisa suara, termograpy, dan gesture.

\subsection{Pendeteksi kebohongan berdasarkan Konduktivitas kulit.}

Pendeteksi kebohongan berdasarkan daya hantar listrik pada kulit, sering disebut dengan Lie detector EDR ( Electroderma Respon). Pendeteksi kebohongan ini memanfaatkan sifat kelistrikan pada kulit manusia. Kulit manusia dianggap dapat menghantarkan arus listrik dengan resistansi tertentu. Resistansi pada kulit manusia akan berubah ubah tergantung banyak atau sedikit keringat pada kulit manusia. Orang dalam berbohong akan lebih berkeringat dibanding dengan kondisi tidak berbohong. Keringat merupakan larutan garam (elektrolit ) yang secara kelistrikkan memiliki properti tahanan listrik [6,7]. Pada bagian kulit tertentu yang dianggap memiliki kelenjar keringat paling sensitive atau konsentrasi keringat paling tinggi dipasang konektor yang langsung terhubung dengan detektor (telapak tangan), tujuannya adalah mendapatkan respon yang maksimal [8]. Salah satu jenis EDR detector adalah GSR (Galvanic Skin Respon) alat ini sangat sensitive terhadap perubahan resistansi atau konduktivitas kulit. Untuk menentukan apakah orang yang diinvestigasi berbohong atau tidak, dilakukan dengan mengamati perubahan SCL respon (skin conduktivitas level), yang distimulus dengan pertanyaan tertentu. [9], bentuk signal respon konduktivitas kulit ditunjukan pada Gambar 2.

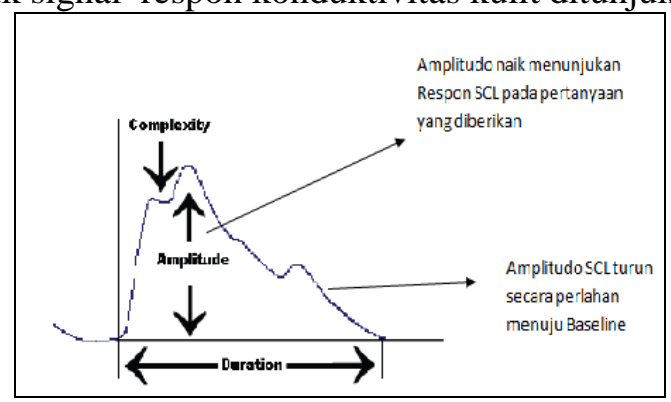

Gambar 2 Respon SCL ( Skin Conduktivitas Level ,sumber [8] )

Pertanyaan penstimulus respon SCL terdiri atas tiga jenis pertanyaan : (1) Pertanyaan yang relevan pertanyaan yang berkaitan langsung dengan permasalahan,(2) Pertanyaan control, pertanyaan yang dimaksudkan sebagai pembanding pertanyaan relevan. (3) Pertanyaan Netral, pertanyaan yang tidak berkaitan permasalahan. Pada test uji kebohongan pertanyaan tersebut dikenal dengan CQT (Control Question Test). Berdasarkan urutan atau komposisi pertanyaan, CQT dibagi menjadi dua yaitu, ZCT ( Zona Comparison test) dan MGQT (Multiple General Question Test). Pada ZCT komposisi pertanyaannya : CRCRCRCR ( C: pertanyaan control, R: Pertanyaan Relevan), sedang pada MGQT komposisi pertanyaannya : RRCRRCRRC [10].Untuk melakukan penilaian / pendeteksian apakah yang bersangkutan berbohong atau tidak, salah satunya dengan menggunakan 7 - posisi skor ( 7-position scorring), dengan menggunakan 7 derajat nilai $(-3,-2,-1,0,1,2,3)$. Ketentuan pemberian skor adalah sebagai berikut : 
- Membandingkan SCR ( skin conductive respon ) untuk relevan pertanyaan, dengan SCR untuk pertanyaan control terdekat.

- Untuk amplitudo SCR yang satu dua kali lebih besar dari amplitude SCR yang lain, maka diberikan skor $=1$.

- Untuk amplitudo SCR yang satu tiga kali lebih besar daripada amplitudo SCR yang lain maka skor 2.

- Untuk amplitudo SCR yang satu empat kali lebih besar dari yang lain, maka skor 3

- Amplitudo sama, maka skor 0

- Pemberian tanda positive dan negative, berkaitan arah perubahan untuk nilai pertanyaan relevan lebih besar pertanyaan control diberikan tanda negative, sebaliknya untuk pertanyaan control yang lebih besar diberikan nilai positif.

Penentuan derajat kebohongan dilakukan dengan melihat chart polygraph, semakin besar nilai scoring maka indikasi kearah kebohongan semakin kuat. Penskoran dilakukan untuk setiap pertanyaan relevant [11].

\subsection{Pendeteksi Kebohongan Berdasarkan isi tulisan.}

Disamping mengamati respon fisiologi, untuk mendeteksi kebohongan juga dapat dilihat dengan menganalisa isi tulisan seseorang. Pada metode ini subjek yang akan diinvestigasi diminta untuk membuat tulisan yang memaparkan ceritanya. Salah satu metode untuk menganalisa cerita dalam sebuah tulisan, dengan mengamati penggunaan kata dan gaya bahasa dalam tulisan tadi. Dalam menyimak maksud dibalik sebuah cerita, menganalisa penggunaan kata kata dalam cerita tersebut jauh berarti dibanding menyimak arti frase secara keseluruhan [12].Salah satu aplikasi untuk menganalisa isi tulisan adalah LIWC ( Linguistic Inquery and Word Count), LIWC adalah sebuah program computer yang digunakan untuk menganalisa teks, berkaitan dengan penggunaan kata kata tertentu yang dikaitkan dengan katagory tertentu, misalnya katagory emosi negative ( eg: sad, angry), katagory emosi positif ( eg: Happy, laugh), katagory standard fungsi kata, katagori religius, dan lain lain. LIWC akan menghitung presentase pengunaan kata kata tertentu, yang selanjutnya digunakan untuk menentukan kebenaran sebuah cerita [13] . Kebohongan juga bisa diungkap lewat analisa gaya bahasa, Pronoun, negasi, konjungsi, preposisi dan beberapa kata yang memiliki makna khusus, dapat digunakan untuk mengungkap apakah sebuah tulisan mengandung kebohongan. Beberapa kata khusus yang dimaksud antara lain seperti (eg. "but", " except", "without”, "exclude”), kata kata yang cenderung bermakna negasi atau sangkalan[14]. Newman, Pennebaker, Berry, dan Richards, mengungkapkan orang yang bercerita dengan kebenaran umumnya mengacu pada kepemilikan diri yang bersangkutan, sehingga umumnya mengunakan kata pronoun orang I , dan korelasinya positive dengan kebenaran cerita. Pengunaan kata ganti orang pertama juga dikaitkan dengan sebuah bentuk ekspresi pengakuan ( tanggung jawab) sehingga orang yang berbohong akan menghindari pengunaan kata ganti orang pertama dalam ceritanya, sebagai bentuk penyembunyian diri $[13,15,16,17]$.Penelitian lain juga mengungkapkan bahwa, seorang yang melakukan kebohongan akan merasa cemas,khawatir,kondisi ini dapat diamati dari pola gaya bahasa yang digunakan dan kata kata yang digunakan cendrung mengambarkan emosi negative ( eg : hate, worthless, sad ) [18]. Newman M.L [13] melakukan sebuah penelitian pengujian kebohongan seseorang berdasarkan isi uraian tulisan yang dibuat. Metode yang digunakan adalah partisipan diminta untuk membuat 2 topik uraian, setiap uraian tersebut dianalisa dengan program LIWC untuk menentukan tingkat kebohongan dalam uraian tersebut. Disisi lain partisipan juga diminta untuk mempresentasikan uraian yang dibuat dihadapan 9 orang penilai yang ahli dalam polygraph tes ( test kebohongan ). Para ahli akan memberikan penilaian apakah subjek tersebut berbohong atau tidak. Berdasarkan analisa akhir pada penelitian tersebut menunjukan keakuratan LIWC : 67\% sedangkan keakuratan juri 52\%. Kesimpulan yang dapat diambil dalam penelitian ini adalah, indikator kebohongan berdasarkan isi uraian sebuah tulisan adalah : (1) Sangat minim menggunakan kata kata yang kaitan dengan

IJCCS Vol. 6, No. 2, July 2012: 35 - 46 
pronoun orang pertama tunggal (e.g., I, me, my), (2) Minim menggunakan kata yang mengacu pada pronoun orang ketiga (eg. He, she, they ), (3) Minim exlusive words ( eg. but, except, without ), (4) Banyak menggunakan kata yang berkaitan dengan motion ( eg. Walk, move, go).

\subsection{Pendeteksi Kebohongan Berdasarkan Bentuk Tulisan Tangan.}

Seperti yang diketahui bentuk tulisan tangan juga dapat digunakan untuk mengenali karakter atau kepribadian, kondisi mental seseorang. Salah satu ilmu yang mempelajari kepribadian,watak, kondisi mental seseorang berdasarkan bentuk tulisan tangan dikenal dengan grafologi. Dengan tulisan tangan dapat diketahui beberapa hal diantaranya : social skill, gaya berpikir ( thingking style), prestasi (achievements), kebiasaan kerja ( work habits), kejujuran. Analisa tulisan tangan dewasa ini sudah dilakukan dengan mengunakan program komputer, dengan menganalisa beberapa feature diantaranya : (1) ukuran huruf, (2)kemiringan tulisan, (3) Baseline, (4) Spasi antar kata maupun antar huruf dalam sebuah kata, (5) tekanan pena[19].

Seorang psikolog Israel Gil Luria menemukan bahwa tulisan tangan dapat mendeteksi kebohongan. Luria mengatakan, analisa dilakukan dengan meneliti tekanan alat tulis pada kertas dan kebohongan menurut Luria lebih banyak menggunakan aspek kognitif manusia. Seseorang harus membuat cerita yang meyakinkan, yang seolah benar, dan tentu saja kebohongan tersebut bertentangan dengan nurani orang tersebut. Penelitian ini menggunakan sensor pada sebuah meja yang mampu menilai tekanan tangan seseorang saat menulis di sebuah kertas. Hasil sensor tersebut itulah yang dijadikan patokan untuk menganalisa kebohongan. Dalam penelitian ini sudah menggunakan bantuan program computer, ComPET (Computer PenmanShip Evaluation Tool), program ini menganalisa hubungan antara otak ( bagian yang berkaitan kognitiv manusia) dengan tangan manusia [20] . Adapun dasar dari penelitian ini adalah adanya penelitian yang menunjukan, kebohongan memiliki relasi positif dengan respon cognitive, pada orang yang berbohong akan terjadi usaha ekplorasi aspek kognitifnya secara tidak wajar, dengan tujuan untuk menutupi kebohongannya [ 21,22]. Dalam penelitian [19] juga menganalisa tulisan tangan untuk mengenali kepribadian seseorang dengan mengunakan metode segmentasi dengan menggunakan vector mechine. Tulisan tangan ditangkap dengan dengan kamera, image tulisan kemudian disegmentasi selanjutnya diektraksi featurenya. Berdasarkan feature tersebut, SVM ( Support Vector Mechine), tujuan menganalisa tulisan tangan untuk menentukan kepribadian penulisnya. Dapat disimpulkan karakter kepribadian seseorang berdasarkan feature tulisan tangan yang ditunjukan pada Tabel 1.

Tabel 1 . Personality berdasarkan Tulisan tangan.

\begin{tabular}{|l|l|l|}
\hline No & $\begin{array}{l}\text { Feature (writng } \\
\text { catagories) }\end{array}$ & Psycholocical Personality Behavior \\
\hline 1 & Large Letters & Likes being noticed, stand out in a crowd \\
\hline 2 & Small Letters & $\begin{array}{l}\text { Introspective,not seeking } \\
\text { attention,modest }\end{array}$ \\
\hline 3 & Medium Letters & Adaptable,fits into a crowd,practical \\
\hline 4 & Right Slant & Sociable,responsive, friendly \\
\hline 5 & Left Slant & Reserved,observant \\
\hline 6 & Vertical & Practical, independent,controlled \\
\hline 7 & Light Pen Presure & Strong emotion, successful \\
\hline 8 & Heavy Pen Presure & Try to avoid energy draining situations \\
\hline 9 & Far Spacing letters & Openness of sentiment, intelligence \\
\hline
\end{tabular}

Penelitian [19], analisa tulisan tangan yang secara khusus tidak ditujukan untuk mendeteksi kebohongan. Namun apabila dikaitkan dengan ulasan [20], ditemukan kesamaan yaitu berdasarkan feature tekanan tulisan ( pada tekanan berat) menunjukan si penulis sedang 
berusaha untuk menghidar dari situasi yang tidak menyenangkan, dalam artian yang bersangkutan dalam kondisi tertekan. Secara Psychopisiology merupakan indikator kebohongan. Penelitian lain [23] serupa dengan penelitian [19], dalam penelitian ini dikembangkan tehnik otomatis untuk menentukan karakteristik orang berdasarkan tulisan tangan. Metode ini kemudian disebut dengan AHWAS (Automated Handwriting Analysis System). Dalam penelitian ini mengunakan RGB filter untuk ekstraksi text dari tulisan tangan, kemudian diidentifikasi 8 feature. Feature yang digunakan adalah : ukuran huruf, baseline, Tekanan tulisan, kemiringan, jumlah koma, spasi antar kata, margin, dan kecepatan tulisan tangan. Berkaitan dengan kebohongan, salah satu feature secara spesifik digunakan untuk mendeteksi kebohongan yaitu Kecepatan tulisan. Feature kecepatan tulisan seseorang menunjukan, bahwa pada tulisan tangan dengan kecepatan pelan menunjukan kepribadian yang cerdas namun tidak komunikatif, sedangkan tulisan tangan yang cepat menunjukan kepribadian yang malas,dan berbohong. Untuk mengukur kecepatan tulisan tangan, digunakan dua algoritma, pertama didasarkan pada perubahan kerapatan ( density) tinta dan yang kedua didasarkan pada panjang coretan setiap 20 fixels.

\subsection{Pendeteksi Kebohongan Berdasarkan Analisa Suara.}

Analisa suara dapat dijadikan alternative pendeteksi kebohongan,prinsipnya sama seperti tes polygraph yang lain, suara mengindikasikan kondisi mental seseorang. Berkaitan dengan deteksi kebohongan salah satu instrument yang berbasiskan analisa suara adalah VSA ( Voice stress Analyser). alat ini diklaim sangatlah handal untuk mendeteksi stress dan sekaligus juga dipromosikan untuk mendekteksi kebohongan. Analisa suara untuk mengenali Kondisi mental seseorang, dikaitkan perubahan microtremor pada otot otot yang berkaitan dengan produksi suara. Microtremor adalah amplitudo rendah pada proses osilasi pada otot otot tertentu, termasuk diantaranya otot yang menghasilkan suara. Pada kondisi normal frekwensi microtremor berkisar ( $8 \mathrm{~Hz}-14 \mathrm{~Hz}$ ). Pada saat tubuh mengalami peningkatan stress, maka getaran microtremor akan menunjukan perubahan secara karakteristik, yaitu frekwensi akan naik sedang amplitudo akan turun. Karakter microtremor ini dijadikan dasar untuk mengenali stress pada manusia, merupakan indikasi kebohongan, ditunjukan pada gambar 3 dan 4 [24].

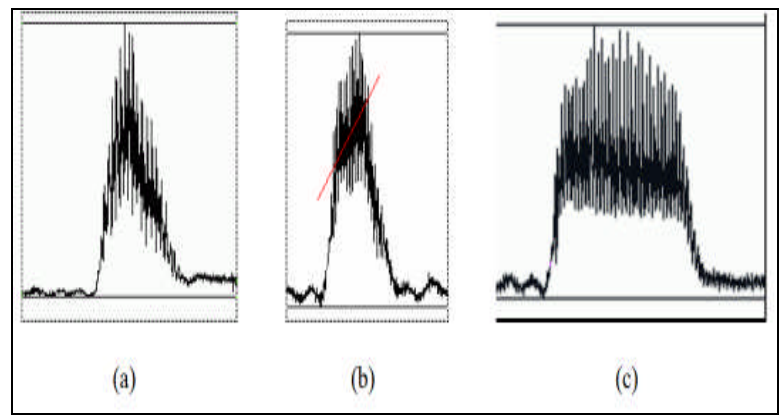

Gambar. 3 Gelombang suara dengan katagori

(a)stress ringan , (b)stress menengah,(c)stress berat. ( sumber : [24])

Walaupun VSA tidak membutuhkan kontak langsung dengan orang yang sedang dites, namun peran seorang penguji sangatlah penting dalam menentukan keberasilan tes. Pada tahap awal seorang penguji VSA akan mengadakan sebuah pre test interview, tujuan test ini adalah sebagai tes pendahuluan untuk mempersiapkan tes tes berikunya. Dalam Pre tes seorang penguji harus menunjukan diri mereka dihadapan orang yang akan ditest bahwa mereka adalah orang orang yang benar benar ahli, sehingga membawa dampak psikologis pada orang yang akan dites, pada orang yang tidak bersalah akan semakin tenang, sebaliknya pada orang yang berbohong akan semakin panik dan gelisah. Tahap berikutnya adalah test inti, penguji akan mengajukan pertanyaan ( protocol Question), serangkian pertanyaan yang disusun dalam urutan

IJCCS Vol. 6, No. 2, July 2012: 35 - 46 
tertentu. Kadang protocol question disusun secara khusus untuk situasi tertentu. Dalam pelaksanaan tes utama jumlah protocol question berkisar $7-31$ pertanyaan. Seperti halnya pada test dengan polygraph EDR,ECR .[25].

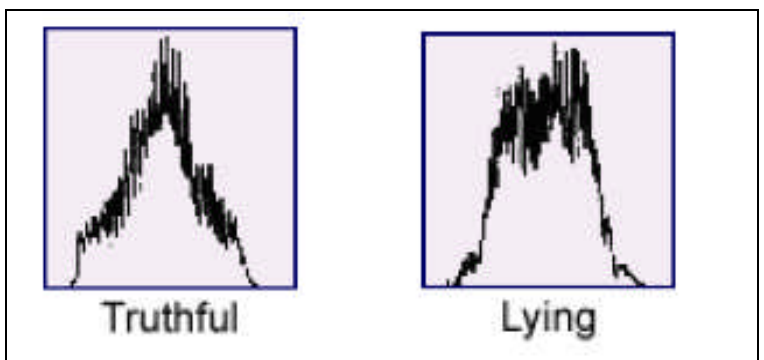

Gambar . 4 . Bentuk gelombang suara Tidak berbohong dan berbohong. ( sumber : [24] )

Pada gambar 5 dibawah menujukan beberapa contoh bentuk signal analisa suara, pada saat subjek diinvestigasi dengan protocol question. (Tanda + : Tidak Bohong, Tanda - : Bohong ).

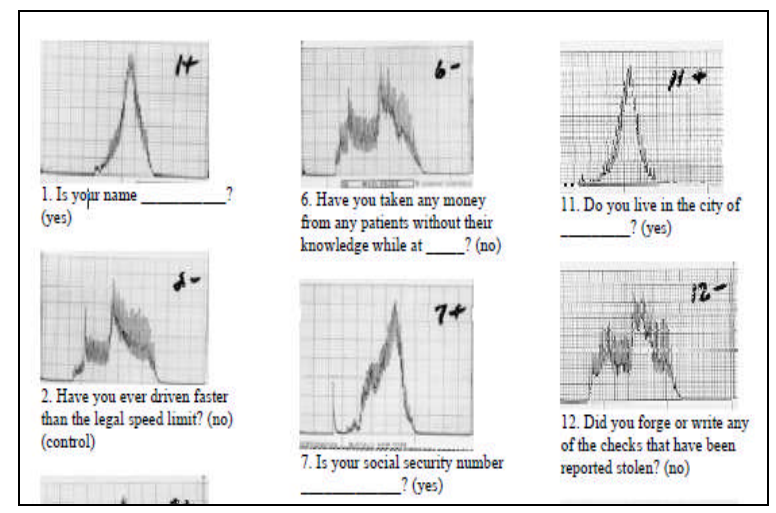

Gambar. 5. Contoh gelombang suara hasil evaluasi VSA ( sumber :[25])

\subsection{Pendeteksi kebohongan Berdasarkan Image infrared (Termograpy)}

Teknologi Infrared Image ( IR image), merupakan teknologi yang mengembangkan analisa image yang dikaitkan panas permukaan sebuah benda (Termogram). Prinsip dasar dari Infrared image, adalah observasi pada benda. Semua benda seperti yang diketahui memancarkan gelombang elektromagnetik, dimana gelombang EM tersebut selalu berkaitan dengan temperatur benda tersebut, dan temperature merupakan representasi energy dalam benda, sehingga dengan analisa IR image kita dapat memprediksi kondisi objek yang diamati [26] . Salah satu manfaat Infrared image adalah untuk mendeteksi kebohongan, perubahan kondisi mental ( tingkat strees ) direpresentasikan dengan perubahan panas pada kulit wajah [27]. Dalam penelitian ini dinyatakan pada orang yang berbohong, otomatis akan mengalami tekanan mental, stress meningkat. Meningkatnya stress ditunjukan dengan meningkatnya kecepatan sirkulasi darah dibawah permukaan kulit. Hubungan antara perubahan kecepataan sirkulasi darah dengan perubahan panas pada kulit dinyatakan dengan persamaan (1).

$$
\frac{d V_{S}}{d t}=\frac{T_{B}\left(C_{S}+K_{c} /(3 d)\right)-C}{\left(T_{B}-T_{S}\right)^{2}} \frac{d T_{S}}{d t}
$$


Dimana :

$\mathrm{dV}_{\mathrm{s}} / \mathrm{dt}=$ secara fisis menyatakan perubahan kecepatan sirkulasi darah

$\mathrm{dT}_{\mathrm{s}} / \mathrm{dt}=$ secara fisis menyatakan perubahan panas pda sebuah area kulit.

TB : Temperature core kulit

TS : temperature kulit pada waktu tertentu

Cs : Kapasitas Panas Kulit

Kc : Ketebalan Kulit ( Konduktivitas panas kulit : $0.168 \mathrm{Kcal} / \mathrm{m} / \mathrm{h} / \mathrm{K}$ )

$\mathrm{d}$ : Kedalaman titik "core" temperatur dari permukaan kulit

Berdasarkan persamaan tersebut diketahui hubungan antara perubahan panas kulit, dengan perubahan kecepatan sirkulasi berbanding lurus, artinya semakin cepat sirkulasi darah maka akan semakin panas pula permukaan kulit. Di sisi lain semakin stress seseorang maka kecepatan sirkulasi darah akan meningkat. Hal ini dijadikan dasar untuk mendeteksi kebohongan. Subjek ditest dengan menggunakan soal soal ( ZCT dan GKT ) [10,11], kemudian dilakukan pengamatan dengan merekam subjek selama menjalani tes. Signal panas pada daerah sekitar mata diamati, untuk mendapatkan bagaimana fluktuasi kecepatan sirkulasi darah pada daerah tersebut, terjadinya kecemasan atau gelisah bisa analisa dengan mengetahui fluktuasi kecepatan aliran darah pada area tersebut. Dalam pengambilan data dilakukan satu batasan bahwa subjek tidak boleh menggunakan kaca mata selama tes, karena glass tidak bisa ditembus oleh spektrum menengah atau panjang dari gelombang infrared. Observasi pada daerah sekitar mata menyatakan disana terdapat dua kondisi respon physiopsikologi. Pada tahap awal melakukan tes hampir pada semua subjek mengalami kenaikan respon secara sedang, sedangkan pada tahap selanjutnya terdapat perbedaan, sebagian responnya naik namun tetap dalam tingkat perubahaan sedang. Sedangkan pada sebagian subjek juga mengalami kenaikan drastis. Perbedaan respon ini dijadikan dasar untuk melakukan klasifikasi, pada subjek yang mengalami kenaikan lebih curam /drastis di klasifikasi subjek yang berkecendrungan berbohong. Gambar 6 menujukan subjek yang berbohong, pada tahap awal ( question session) perubahan panas kulit normal ditunjukan dengan kemiringan garis masih landai, pada tahap berikutnya kemiringan garis naik. Hal ini mengindentifikasikan subjek sedang berbohong.

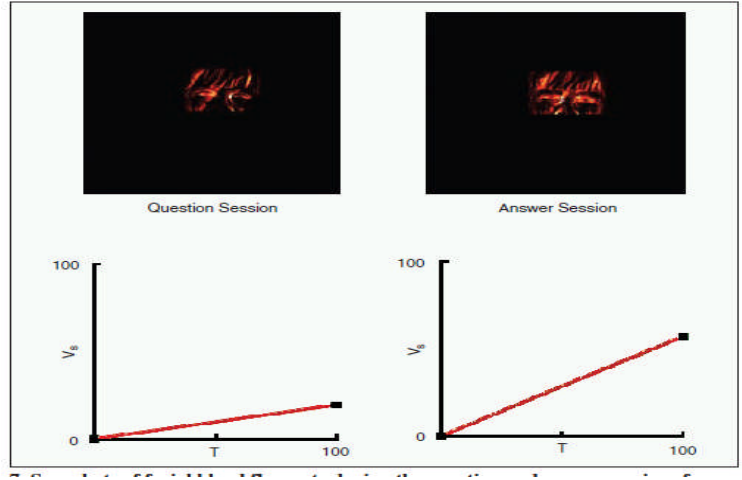

Gambar 6. grafik perubahaan panas kulit pada tahap Question session dan answer session.yang menunjukan kebohongan ( sumber :[27])

\subsection{Pendeteksi Kebohongan Bedasarkan Gesture/ bahasa Tubuh.}

Bahasa tubuh berkaitan erat dengan emosi, sehingga membaca bahasa tubuh juga merupakan sebuah metode untuk mengungkap apakah seseorang itu berbohong atau tidak. Dalam penelitian Prof Abert Mehrabian menyatakan bahwa, dalam komunikasi yang dilakukan secara langsung (berhadap hadapan), pesan yang disampaikan dapat diterima dengan

IJCCS Vol. 6, No. 2, July 2012: 35 - 46 
indentifikasi sebagai berikut: $7 \%$ melalui kata kata yang diucapkan, $38 \%$ melalui intonasi, dan $55 \%$ melalui gerak gerik ( body language atau gesture). Dalam kondisi sadar atau tidak manusia berkomunikasi tidak bisa dilepaskan dari perasaan, dan perasaan dinyatakan dalam bentuk gerak tubuh. Pola gerak tubuh tertentu memiliki arti tertentu. Berkaitan dengan deteksi kebohongan dengan gesture, berikut ini beberapa deskripsi tentang gesture atau bahasa tubuh untuk meneteksi kebohongan :

1. Suspect, cenderung mengangguk atau mengerakan kepala dengan irama /pola yang tidak konsisten. Sebagai contoh : seorang pencuri ditanya "Anda yang telah mengambil tas ", mungkin ia secara verbal akan menjawab " tidak", namun pada saat yang bersamaan kepala bergerak naik turun, seolah olah membenarkan " ya saya mengambilnya".

2. Suspect, cendrung mengosok gosok dahi atau cendrung memukul lehernya sendiri.

3. Suspect, cendrung menggangukan kepala namun dengan delay / penundaan setelah ditanya sesuatu. Orang yang tidak bersalah akan langsung menganggukan kepala sebagai tanda persetujuan terhadap sebuah pernyataan. Namun orang yang berbohong, juga akan mengangguk namun setelah jeda beberapa lama ( Tidak otomatis )

4. Suspect Memegang hidung berkali kali, contoh kasus dua orang psikolog Hirsch dan wolfe mengamati testemoni presiden Bill Clinton tentang affair dengan Monica Lewinski . Disimpulkan Presiden Clinton bohong, indikasinya dalam waktu 4 menit, Presiden Clinton memegang hidung 26 kali.

5. Meletakan tangan pada daerah sekitar mulut.

Matsumato [28] melakukan sebuah penelitian untuk mendeteksi kebohongan, dalam penelitian ini diamati gesture ekspresi wajah. Yang dimaksud dengan gesture pada ekspresi emosi wajah adalah: makro, mikro ekpresi, ekspresi ekspresi halus. Ekspresi tersebut sifatnya universal tidak membedakan latar belakang kebudayaan, ethik, kebangsaan, jenis kelamin, agama,umur, maupun variable demografik lainnya. Dalam penelitian ini kondisi subjek dibuat mendekati kondisi real, dimana subjek yang akan diinvestigasi, terlebih dahulu sudah dimotivasi untuk berkarakter sebagai seorang pembohong. Sebanyak 20 orang dijadikan sebagai subjek yang diinvestigasi, 10 orang dengan skenerio kriminal dan 10 orang lainnya option skenario, kemudian diamati gesture pada ekpresi wajah emosi dengan membandingkan kecocokan ucapan dengan ekspresi wajahnya. Metode pengujian apakah subjek bohong atau tidak dalam penelitian ini dilakukan oleh investigator yang sudah terlatih (tidak menggunakan mesin / instrument bantu), sehingga keakuratan analisa tergantung pada keahlian investigator. Yang diperhatikan adalah kecocokan respon ucapan dari subjek yang diinvestigasi dengan ekspresi emosi wajah universal tadi. Berkaitan dengan pengenalan gesture pada wajah, dalam penelitian computer vision pengenalan micro ekspresi wajah sudah dilakukan, walaupun penelitian ini belum dikaitkan secara khusus untuk mendeteksi kebohongan. Beberapa penelitian tentang gesture ekpresi wajah diantaranya : [29] membahas pengenalan gesture mikroekpresi pada wajah dengan menggunakan kamera kecepatan tinggi (200 fps ) dan 3D gradient descriptor, tujuan penelitian ini adalah mengenali karakteristik seseorang berdasarkan mimik wajahnya. [30] Melakukan penelitian untuk mengenali ekspresi makro dan mikro pada wajah, dalam penelitian ini dilakukan otomatis spotting (Temporal segmentasi ) pada ekpresi wajah dalam sebuah rekaman video. Metode yang digunakan juga melibatkan pengukuran kerutan pada kulit wajah yang diakibatkan perubahan ekpresi pada wajah. Berdasarkan hal tersebut kedepan sangat memungkinkan menerapakan aplikasi computer vision tentang pengenalan gesture untuk menedeteksi kebohongan.

\subsection{Perbandingan Antar Metode.}

Masing masing metode memiliki kelebihan dan kekurangan, tabel 2 menguraikan beberapa kelebihan dan kekurangan metode tersebut. 
Tabel 2 Perbandingan kelebihan dan kelemahan Metode Deteksi Kebohongan

\begin{tabular}{|c|c|c|}
\hline No & variabel & Keterangan \\
\hline 1 & Kelebihan & $\begin{array}{l}\text { 1. Metode Konduktivitas Kulit : Sudah umum digunakan dalam } \\
\text { polygraph test } \\
\text { 2. Metode Analisa Isi ( content) tulisan : (1) Tidak bersifat invasive, } \\
\text { sehingga subjek yang sedang dites merasa lebih nyaman. (2) } \\
\text { Penilaian kebohongan sudah dilakukan dengan bantuan computer, } \\
\text { untuk menghidari subjektivitas. (3) lebih murah. } \\
\text { 3. Metode Bentuk Tulisan Tangan : (1) Keakuratan sangat baik (2) } \\
\text { Tidak bersifat invasive, sehingga subjek yang sedang dites merasa } \\
\text { lebih nyaman. (3) Penilaian kebohongan sudah dilakukan dengan } \\
\text { bantuan computer, untuk menghidari subjektivitas. (4) Tidak } \\
\text { dipengaruhi kesehatan subjek. } \\
\text { 4. Analisa Suara : (1) Keakuratan sangat baik dan sudah diterima } \\
\text { secara luas dipengadilan sebagai barang bukti dibeberapa negara ( } \\
\text { USA). (2) Penilaian sudah mengunakan computer untuk } \\
\text { menghindari subjektivitas.(3) Tidak harus menggunakan Question } \\
\text { protocol tertentu } \\
\text { 5. Analisa image infrared : (1) Keakuratan sangat baik . (2) Tidak } \\
\text { bersifat invasive, sehingga subjek yang sedang dites merasa lebih } \\
\text { nyaman } \\
\text { 6. Analisa Gesture : (1) secara ilmu pschopsysilogy diakui sebagai } \\
\text { dasar yang sangat baik untuk mendeteksi kebohongan, ( 2) Tidak } \\
\text { harus tergantung pada Question protocol tertentu. }\end{array}$ \\
\hline 2 & Kekurangan & $\begin{array}{l}\text { 1. Metode Konduktivitas Kulit: (1)Persiapan agak rumit, pada bagian } \\
\text { tertentu dari tubuh.(2)Bersifat invasive.(3)Terpengaruh lingkungan } \\
\text { (4)Terpengaruh pada kesehatan subjek } \\
\text { 2. Analisa Isi ( content) tulisan : Kemungkinan orang masih bisa } \\
\text { dilatih untuk mengelabui alat. } \\
\text { 3. Metode Bentuk Tulisan Tangan : Belum ada alat secara khusus } \\
\text { untuk mendeteksi kebohongan, SVM digunakan untuk melihat } \\
\text { kepribadian cecara umum ( walaupun didalamnya ada kaitan dengan } \\
\text { deteksi kebohongan) } \\
\text { 4. Analisa Suara : (1) dipengaruhi oleh kesehatan subjek yang akan } \\
\text { dites } \\
\text { 5. Analisa image infrared : (1) Sebelum tes subjek harus puasa, untuk } \\
\text { mengeliminasi panas dari metabolism. (2) Subjek tidak boleh } \\
\text { berkaca mata, poni rambut terlalu panjang. } \\
\text { 6.Analisa Gesture: (1) Assesment masih dilakukan secara manual, } \\
\text { sehingga subjektivitas menjadi berpengaruh. }\end{array}$ \\
\hline
\end{tabular}

\section{KESIMPULAN}

Metode uji kebohongan sebenarnya adalah sebuah pendekatan untuk memprediksikan apakah subjek yang diinvestigasi sedang berbohong atau tidak. Metode pengujian kebohongan dilakukan dengan mengamati respon tubuh pada saat berbohong, secara umum orang sedang berbohong akan mengalami tekanan ( stress) dan manifestasi stress bisa ditanggap dalam banyak bentuk ( produksi keringat, perubahan bentuk tulisan tangan, panas pada kulit, perubahan suara, gesture,dan lain lain). Respon tubuh diamati dan dijadikan dasar analisa untuk menilai seseorang berbohong atau tidak. Setiap metode memiliki kekuatan dan kelemahan masing masing, secara umum kelemahan metode deteksi kebohongan adalah pada saat proses penilaian terutama yang evaluasi dilakukan secara manual. Akan sangat baik dalam dalam test uji kebohongan mengabungkan beberapa metode, kemungkinan akan menghasilkan hasil yang lebih optimal.

IJCCS Vol. 6, No. 2, July 2012 : 35 - 46 


\section{SARAN}

Ada beberapa metode yang secara dasar keilmuan ( pshycopsiologi) diyakini sangat baik untuk mendeteksi kebohongan, namun pada saat proses assessment menggunakan penilaian manual. Walaupun yang menilai adalah para pakar, tetapi unsur subjektivitas dan keterbatasan manusia masih menjadi kendala. Akan sangat baik apabila evaluasinya menggunakan bantuan computer. Misalkan pada metode pendeteksi wajah berdasarkan gesture wajah, sangat memungkinkan untuk mengembangkan evaluasi berbasis teknologi computer. Dengan memadukan teknologi computer vision, video processing dengan pshycopsiologi, dapat diharapkan sebuah lie detector yang lebih baik.

\section{DAFTAR PUSTAKA}

[1] Martin S, 2009, The Black Book of Lie Detection : Effective Technique from Profesional LieDetector, http://i-sight.com/lie-detection/establishing-rappor., diakses tanggal 24 november 2011.

[2] Berntson, G. G., Cacioppo, J. T. and Sarter, M. ,2003, Psychophysiology in Biological Psychiatry,John Wiley \& Sons, Ltd, Chichester.

[3] Harahap A.P, 2011, Penggunaan Alat pendeteksi Kebohongan pada Proses Peradilan Pidana Dikaitkan dengan UU No 8 Tahun 1981 Tentang Hukum Acara Junto UU No 11 Tahun 2008 Tentang Informasi dan Transaksi Elektronik, Skripsi,Fakultas Hukum Universitas Sumatera Utara, Medan.

[4] Cacciopo J T, Berntson G G, Louis G, Tassinary L G, 200, Handbook of Psychophysiology „Ed 2 , Cambiage University Press, New York.

[5] Boucsein W , 1992, Electroderma Activity “, New York, Plenum Press, New York.

[6] Edelberg R , 1972, Electrical properties of Skin , in C.C Brown (Ed) Methods in Psychophysiology, Hal 1-53.

[7] Venables P.H , Christine M.J , "Electroderma Activity”, in Martin and Venebles P.H ( Eds) Tehniques in Psychophysiology, New York, NY Welly , (1980)

[8] Mark H , Raymond N, Donal K, Charles H R, 2010 ,An EDA Primer Polygraph Examiner , http://www.limef.com/downloads/handler-eda.pdf, Diakses tanggal 26 November 2011

[9] Westeyn T, Presti P, Starner T, 2005, Action GSR : A Combination Galvani Skin Response - Accelerometer for Physiological Measurement in Active Environment, http://www. citeseerx.ist.psu.edu/.../download?...pdf, diakses 24 november 2011.

[10] Slavkovic A., 2002 , Evaluating Polygraph Data , Technical Report 766, Departement of Statistics, Carnegie Mellon University.

[11] Gordon N.J, 1999, The Academy for Scientific Investigate Training's Horisontal Scoring System and Examiner's Algorithm System for Chart Interpretation, Polygraph, No.1, Vol. 28, Hal 56-64.

[12] Chung C, Pennebeker J, 2007, The Psychological Function of Function Words, K. Fiender , Social Communication ( pp.343-359), Psychology Press, New York.

[13] Newman, M.L., Pennebaker, J.W., Berry, D.S, Richards, J.M, 2003, Lying words: Predicting deception from linguistic styles. Personality and Social Psychology, No 5, vol 29, Hal 665-675.

[14] Pennebaker, J. W., \& King, L. A,1999, Linguistic styles: Language use as an individual difference, Journal of Personality and Social Psychology, Vol 6,Hal 1296-1312. 
[15] Buller, D. B., Burgoon, J. K., Buslig, A., \& Roiger, J, 1996, Testing Interpersonal Deception Theory: The language of interpersonal deception. Communication Theory, vol 6, Hal268-289.

[16] Dulaney, E. F,1982, Changes in language behavior as a function of veracity. Human Communication Research, Vol 9, Hal 75-82.

[17] Knapp, M. L., Hart, R. P., \& Dennis, H. S, 1974, An exploration of deception as a communicationconstruct, Human Communication Research, Vol 1, Hal 15-29.

[18] Ekman, P. (1985/1992). Telling lies: Clues to deceit in the marketplace, politics, and marriage (2nd ed.). New York: Norton.

[19] Prasad S, Singh V.K, Sapre A., 2010, Handwriting Analysis Based on Segmentation Method for Prediction of Human Personality Using Support Vector Machine , International Journal of Computer Application (0975-8887), No. 12Volume 8 , Hal 25-29.

[20] Luria G , Rosenblum S ,2009, Comparing The Hand Writing Behaviours of True and False Writing With Computerized Handwriting Measures, http://www.interscience.wiley, diakses tanggal 7 desember 2011.

[21] Miller G, Stiff J, 1993, Deceptive communication, Vol 14, Sage Publications. Inc, Michigan.

[22] Sporer, S. L., \& Schwandt, B. ,2006, Paraverbal indicators of deception: A metaanalytic synthesis, Applied Cognitive Psychology, Vol 20, Hal 421-446.

[23] Kamath V, Ramanswary N, Karanth P.N, Desai V, kulkarni S.M . , 2011, Development of an Automated Handwriting Analysis System", ARPN Journal Engineering of Applied Sciences, No. 9,Volum. 6, Hal 135-140.

[24] Clifford S Hofkin, Daniel S Benincasa ., “Evaluation of Voice Stress Analisis Technology “, Law Enforcement Analysis Facility Lockheed Martin IT.

[25] Damphouse K R, Pointon L, Upchurch D, Moore R K, 2007 , Assessing The Validity of Voice Stress Analysis Tool in a Jail Setting, This research project was a grant from the National Institute of Justice (2005-IJ-CX-0047)., U.S Departement of Justice, Washington $\mathrm{DC}$

[26] Brent Griffith B, Daniel Türle Dr, Howdy Goudey H, 2001, Infrared Thermografic System, http://www.btech.lbl.gov/papers/46590.pdf , diakses tanggal 18 desember 2011.

[27]Pavlidis I , Levine J ,2002, Thermal Image Analysis for Polygraph Test, IEEE Engineering in Medecine and Biologi, Vol 21, Hal 56-64.

[28] Matsumoto D, Hwang H S, Skinner L, Frangk M G , 2011, Evaluating Truthfulness and Detecting Deception , FBI Law Enforcement Bulletin, Volume 80, Halaman 1-25.

[29] Polikovsky S, Kameda Y ,Otha Y , 2009, Detection and Measurement of Facial Micro Expresion Characteristics for Psychological Analysis, 3rd International Conference on Imaging for Crime Detection and Prevention(ICDP-09), London, march 12.

[30] Matthew Shreve, Sridhar Godavarthy, Vasant Manohar, Dmitry Goldgof, Sudeep Sarkar. “ Toward Macro and Micro Expresion Spotting in Video using Strains Pattern ". http://www.cse.usf.edu , diakses tanggal 22 Desember 2011. 